\title{
Infliximab use in ulcerative colitis flare with clostridium difficile infection: A report of two cases and literature review
}

\author{
Bhupinder S. Romana, Abdulmajeed A. Albarrak, Mohamad H. Yousef, Veysel Tahan \\ Department of Internal Medicine, Division of Gastroenterology and Hepatology, University of Missouri, Columbia, Missouri, USA
}

\begin{abstract}
Clostridium difficile infection (CDI) is a major cause of morbidity and mortality in patients with inflammatory bowel disease (IBD), especially in ulcerative colitis (UC). The incidence and severity of CDI in IBD has shown an increasing trend in the last two decades. Patients with IBD are predisposed to CDI secondary to the recurrent use of antibiotics, corticosteroids, and immunosuppressants and secondary to dysbiosis. It is clinically challenging to distinguish the symptoms of CDI from an IBD flare. The worsening of IBD symptoms demands escalation of steroids or initiation of biologics. However, the management of CDI in IBD, not responding to antibiotics, is not well described beyond a few case reports. We report two cases of CDI with active UC flare. The patients did not respond to antibiotics or intravenous corticosteroids but had rapid resolution of CDI symptoms after receiving infliximab infusion. The optimal dosing and infusion frequency of infliximab in management of CDI in UC/IBD remains to be established.
\end{abstract}

Keywords: Clostridium difficile; comorbidity; dual; infliximab; tumor necrosis; treatment; ulcerative colitis.

Cite this article as: Romana BS, Albarrak AA, Yousef MH, Tahan V. Infliximab use in ulcerative colitis flare with clostridium difficile infection: A report of two cases and literature review. North Clin Istanb 2018;5(3):256-260.

Tnflammatory bowel disease (IBD) patients, espe1 cially those with ulcerative colitis (UC), are at a high risk of developing Clostridium difficile infection (CDI) and related complications. CDI has been reported in $1.8 \%-5.7 \%$ of the patients hospitalized for UC [1]. IBD patients with CDI have poor outcomes with increased severity of relapse, longer hospital stay, and high rates of colectomy and mortality [2]. Approximately $10 \%$ of IBD patients develop CDI at the time of diagnosis or during the course of their disease $[3,4]$. Colon involvement increases the risk of CDI by several fold compared with small bowel disease. Probably due to this reason, UC patients have a higher risk of developing CDI compared to Crohn's disease (CD) patients [1]. IBD patients also have a higher rate ( $8 \%$ vs $1 \%$ ) of asymptomatic carriage of $C$. difficile than the general healthy population
[5]. The management of CDI in IBD, not responding to antibiotics, is a challenge.

Here we report two cases of UC flare secondary to CDI.

\section{CASE REPORTS}

Case 1 - A 21-year-old female with the history of panUC presented with bloody diarrhea. She was having approximately 20 bowel movements a day along with lower abdominal pain, fever, tenesmus, and urgency.

The patient was diagnosed with pan-UC 3 years ago using colonoscopy and mucosal biopsies. She achieved clinical remission with high prednisone dose for 3 weeks with a gradual tapering off and was on maintenance therapy with azathioprine and mesalamine. Due to financial

Received: September 05, 2017 Accepted: November 09, 2017 Online: May 25, 2018

Correspondence: Dr. Veysel TAHAN. Department of Internal Medicine, Division of Gastroenterology and Hepatology, University of Missouri, Columbia, Missouri, USA.

Phone: +1 573 884-6044 e-mail: tahanv@health.missouri.edu

(c) Copyright 2018 by Istanbul Provincial Directorate of Health - Available online at www.northclinist.com 
reasons, she discontinued all her medications after a few months of remission. She stayed in remission until 3 months ago when she was admitted to an outside hospital with fever, abdominal pain, and bloody stools. Stool studies were negative for infection including that with $C$. difficile. Colonoscopy showed mucosal inflammation in the rectum and sigmoid and descending colon. Mucosal biopsies indicated acute or chronic colitis without dysplasia. Intravenous steroids were initiated, and the patient was discharged on oral prednisone with a gradual tapering off. Prior to the current admission, she received two doses of infliximab.

Patient appeared sick on initial presentation. She was afebrile and tachycardic with a heart rate of $112 / \mathrm{min}$ and had soft blood pressure of $98 / 49 \mathrm{mmHg}$ without orthostatic hypotension and $95 \%$ oxygen saturation. Her bowel sounds were hypoactive, and the abdomen was diffusely tender to palpation.

Laboratory workup was significant for an elevated white blood cell (WBC) count of $21,000 / \mu \mathrm{L}$ with left shift, microcytic anemia with hemoglobin of $11 \mathrm{~g} / \mathrm{dL}$, erythrocyte sedimentation rate (ESR) $29 \mathrm{~mm} / \mathrm{h}$, and Creactive protein (CRP) $18 \mathrm{mg} / \mathrm{dL}$. Other renal and liver chemistries were normal. Stool polymerase chain reaction (PCR) was positive for toxin-producing C. difficile with a negative hyper-virulent 027-NAP1-B1 strain. Computed tomography of the abdomen with intravenous contrast (Fig. 1A, B) showed multifocal, moderate mural thickening throughout the colon, most pronounced in the ascending colon. The appendix was dilated with mild periappendiceal fat stranding along with enlarged right lower quadrant mesenteric lymph nodes. Flexible sigmoidoscopy (Fig. 2) showed friable, granular mucosa with pseudo membrane formation, which was consistent with Mayo Class 2 endoscopic disease activity. Mucosal biopsies showed chronic active colitis with moderate ac-
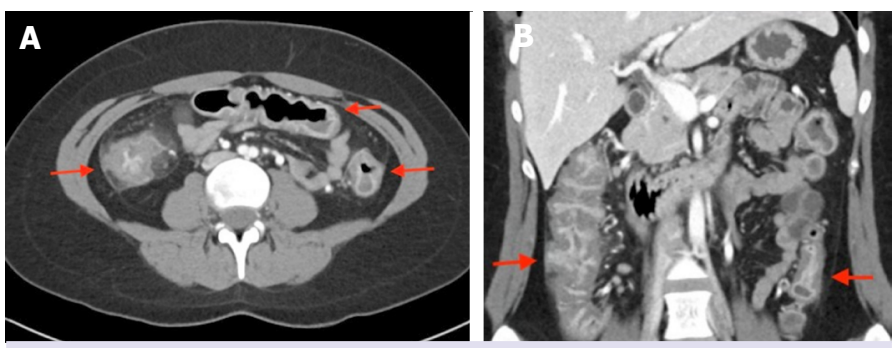

FIGURE 1. CT scan of abdomen and pelvis with intravenous contrast shows moderate wall thickening throughout the colon, most pronounced in the ascending colon. tivity and granulation tissue. The test for cytomegalovirus stain showed negative results.

Treatment was initiated with oral vancomycin and intravenous metronidazole along with aggressive intravenous hydration. General surgery department was consulted, and it recommended against acute surgical intervention. Patient failed to improve over the next 72 $\mathrm{h}$; thus, a decision was made to start intravenous methyl prednisone $40 \mathrm{mg}$ daily with a gradual tapering off. WBC count, ESR, and CRP levels started improving, but diarrhea persisted. Infliximab levels were less than $1 \mathrm{mcg} / \mathrm{mL}$. The patient received a dose of $10 \mathrm{mg} / \mathrm{kg}$ infliximab, resulting in the resolution of diarrhea over the next $24 \mathrm{~h}$. She successfully completed a 2 -week course of vancomycin and metronidazole and had completely recovered from the flare at a follow-up visits after 2 and 6 weeks.

Case 2 - A 19-year-old male with a history of pan-UC presented with diarrhea and abdominal pain. He complained of watery diarrhea, on and off mixed with blood, associated with urgency and lower abdominal pain.

The patient was diagnosed with pan-UC 4 months ago using colonoscopy and mucosal biopsies. Oral mesalamine was initiated, and he achieved a clinical remission within few weeks. He had experienced two episodes of CDI since the onset of UC. The first episode was treated with oral metronidazole and the second with a 4-week taper

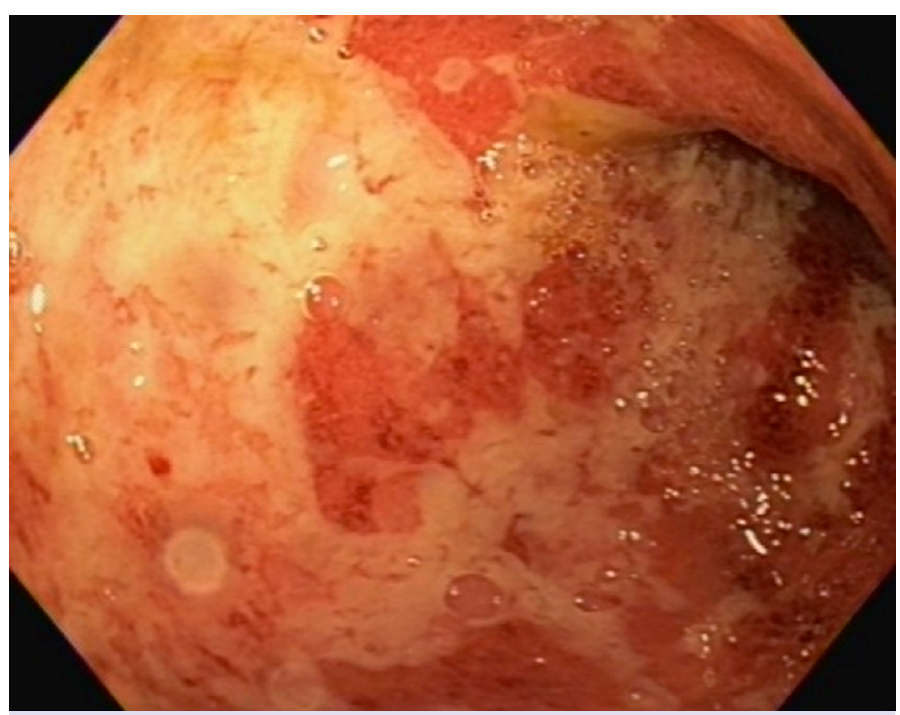

FIGURE 2. Endoscopic view of sigmoid colon showing friable, granular mucosa with pseudo membrane formation consistent with severe Clostridium difficile infection. 
of oral vancomycin. He remained asymptomatic for more than a month.

Patient's vital signs were stable on presentation. There was no fever, tachycardia, or hypotension. Abdomen was tender to palpation with normal bowel sounds. Laboratory workup showed hemoglobin levels of $10 \mathrm{~g} / \mathrm{dL}$ and ESR $25 \mathrm{~mm} / \mathrm{h}$. Other hematology and biochemistries were within the normal range. Stool PCR was positive for toxin-producing $C$. difficile with a negative hyper-virulent strain.

Treatment was initialed with oral vancomycin and intravenous steroids. Patient had resolution of hematochezia, but severe diarrhea persisted. He received 5 $\mathrm{mg} / \mathrm{kg}$ infliximab infusion after 5 days, resulting in complete resolution of diarrhea within $24 \mathrm{~h}$. He was re-evaluated in the clinic after 3 months and continues to do well on infliximab infusion every 8 weeks.

\section{DISCUSSION}

C. difficile is a gram-positive, anaerobic, spore-forming, toxin-producing bacillus transmitted through the fecaloral route. In the late 1970s, it was first recognized as a causative agent of antibiotic-related pseudomembranous colitis [6]. It slowly emerged as the leading cause of gastroenteritis-related mortality, and the incidence of CDI has been steadily rising over the decades. In 2011, $C$. difficile was responsible for approximately half a million cases of infection and 29.000 deaths in the US [7]. Since 2005, the hyper-virulent strain of $C$. difficile, commonly referred as NAP1/B1/027, has been responsible for frequent outbreaks in North America, England, Europe, and parts of Asia [8]. Community-acquired CDI is seen in the absence of antibiotic use. It is also emerging in increasing proportions; a 2011 US study reported an adjusted national rate of 51.9 per 100.000 population [7].

Dysbiosis appears to play a vital role in the pathogenesis of both IBD and CDI [9]. Dysregulation of immune tolerance to the commensal gut microbiota possibly leads to mucosal inflammation in IBD. Reduced microbiota diversity also promotes $C$. difficile transmission and germination. The cytotoxic effects of $C$. difficile toxin damage the epithelial barrier, promote bacterial adhesion, and increase mucosal permeability, thus, contributing to the pathogenesis of IBD [10]. The fundamental question of whether CDI is a cause or outcome of IBD still remains unanswered. CDI may cause superimposed colitis in IBD or might precipitate an IBD flare with two sepa- rate, but simultaneous, ongoing inflammatory processes [10]. Probably this is the reason that UC flare patients co-infected with $C$. difficile have poorer long-term outcomes than those not infected with this bacterium [11]. Another hypothesis is that $C$. difficile might be just a colonizer in IBD patients, and disease flares are completely independent of its presence [10].

It is a diagnostic dilemma to differentiate whether the symptoms are due to a flare of chronic IBD or new CDI. American Collage of Gastroenterology (ACG) 2013 guidelines recommend that all IBD patients with a disease flare or new-onset diarrhea must be tested for CDI (12). PCR detects toxin-producing genes and is currently the preferred test for CDI. It is a rapid test with high sensitivity (>90\%) and high specificity (>95\%) [13]. Enzyme immunoassay detects toxins $A$ and $B$ in stools. It is rapid, cost effective, and has variable sensitivity $(63 \%-94 \%)$ and specificity $(75 \%-100 \%)$ [14]. It is important to emphasize that PCR can detect $C$. difficile isolates that contain inactive toxin genes, which are not actively transcribing toxins, leading to false-positive tests. A positive PCR also cannot differentiate between an asymptomatic carrier and an active infection. Testing should be performed only on unformed stool to reduce the false-positive rates.

An American Gastroenterology Association expert review recommends that IBD should be considered as a severity marker of CDI and vancomycin or fidaxomicin should be considered as first-line antibiotics. Patients with mild to moderate disease are treated with $125 \mathrm{mg}$ oral vancomycin four times a day. Those with severe or complicated disease should be given a higher oral dose of $500 \mathrm{mg}$ vancomycin four times a day combined with 500 $\mathrm{mg}$ intravenous metronidazole 8 hourly and vancomycin enemas along with early surgery consultation [12].

The second important decision is regarding the management of immune suppression with ongoing infection. ACG 2013 guidelines recommend simultaneously starting empirical therapy for CDI and IBD flare in cases of severe colitis while awaiting $C$. difficile test results. The ongoing immunosuppressive medications should be continued while treating CDI. The initiation of corticosteroids or anti-tumor necrosis factor (TNF) therapy is discouraged in the first $72 \mathrm{~h} \mathrm{[12].} \mathrm{Using} \mathrm{a} \mathrm{combination}$ of immunomodulators and antibiotics in CDI tends to have worse outcomes than using antibiotics alone [15]. Intravenous corticosteroids are commonly the first choice in escalation of immunosuppression when CDI 
symptoms do not improve with antibiotics alone. The patient should be monitored closely for worsening of CDI symptoms or impending complications like toxic megacolon or perforation.

Infliximab is a chimeric Ig G4 monoclonal antibody targeting TNF-alpha (TNF-a). It is frequently used for induction of rapid remission in patients with fulminant UC. However, it has not been very well studied for use in UC flare secondary to CDI [16]. Induction of TNF-a by C. difficile toxins A and B in addition to other cytokines in causing inflammation suggests the potential role of anti-TNF therapy in CDI [17]. Anti-TNF therapy was found to be protective against CDI in a study [18]. In another population-based study, infliximab was not found to be associated with an increased risk of developing CDI [19]. Infliximab infusion resulting in therapeutic trough levels resulted in resolution of recurrent CDI symptoms in a single reported case of UC [20]. Infliximab drug level of less than $0.5 \mu \mathrm{g} / \mathrm{mL}$ requires dose escalation or shortening of interval between the infusions [21]. Contrary to the above evidence, Razik et al. reported more episodes of recurrent $\mathrm{CDI}$ in IBD patients on infliximab, whereas those on adalimumab did not show an increased risk. Azathioprine, methotrexate, and cyclosporine did not increase the risk of recurrent CDI [22]. Similarly, Zhang et al. [23] showed an increased risk of CDI in IBD patients on infliximab and antibiotics. A recent population-based study in Canada showed increased risk of CDI among IBD patients who were on corticosteroids or anti-TNF agents [24].

Immunotherapy, with intravenous immunoglobulin (IVIG), has been attempted in recurrent CDI with limited success in small studies $[25,26]$. The rationale is that patients with severe or recurrent CDI have lower serum antitoxin antibody levels [27]. Fecal microbiota transplantation is less effecttive in clearing recurrent CDI in IBD patients than in patients without IBD $(74.4 \%$ vs 92.1\%) [28]. It was also associated with IBD flare in onefourth of the patients in the same study.

There is a paucity of literature on the use of corticosteroids, infliximab, or IVIG in CDI associated with IBD. Furthermore, there is contradicting data on the beneficial effect of infliximab in CDI. Both of our patients did not respond to antibiotics and corticosteroids for $72 \mathrm{~h}$ but showed rapid improvement with infliximab infusion. Checking serum infliximab levels during a flare might be useful in guiding further therapy for CDI. Prospective studies in the future will likely provide more insight on the use of biologics in IBD flare associated with CDI.
Informed Consent: Written informed consent was obtained from the patient who participated in this study.

Conflict of Interest: No conflict of interest was declared by the authors.

Financial Disclosure: The authors declared that this study has received no financial support.

Authorship Contributions: Concept - B.S.R., A.A.A., M.H.Y., V.T.; Design - B.S.R., A.A.A., M.H.Y., V.T.; Supervision - B.S.R., A.A.A., M.H.Y., V.T.; Materials - B.S.R., A.A.A., M.H.Y., V.T.; Data collection \&/ or processing - B.S.R., A.A.A., M.H.Y., V.T.; Analysis and/or interpretation - B.S.R., A.A.A., M.H.Y., V.T.; Writing - B.S.R., A.A.A., M.H.Y., V.T.; Critical review - V.T.

\section{REFERENCES}

1. Nguyen GC, Kaplan GG, Harris ML, Brant SR. A national survey of the prevalence and impact of Clostridium difficile infection among hospitalized inflammatory bowel disease patients. Am J Gastroenterol 2008;103:1443-50. [CrossRef]

2. Ananthakrishnan AN, McGinley EL, Binion DG. Excess hospitalisation burden associated with Clostridium difficile in patients with inflammatory bowel disease. Gut 2008;57:205-10. [CrossRef]

3. Rodemann JF, Dubberke ER, Reske KA, Seo DH, Stone CD. Incidence of Clostridium difficile infection in inflammatory bowel disease. Clin Gastroenterol Hepatol 2007;5:339-44. [CrossRef]

4. Binion DG. Clostridium difficile Infection in Patients with Inflammatory Bowel Disease. Gastroenterol Hepatol (N Y) 2012;8:615-7.

5. Clayton EM, Rea MC, Shanahan F, Quigley EM, Kiely B, Hill C, et al. The vexed relationship between Clostridium difficile and inflammatory bowel disease: an assessment of carriage in an outpatient setting among patients in remission. Am J Gastroenterol 2009;104:1162-9. [CrossRef]

6. Bartlett JG, Chang TW, Gurwith M, Gorbach SL, Onderdonk AB. Antibiotic-associated pseudomembranous colitis due to toxin-producing clostridia. N Engl J Med 1978;298:531-4. [CrossRef]

7. Lessa FC, Mu Y, Bamberg WM, Beldavs ZG, Dumyati GK, Dunn JR, et al. Burden of Clostridium difficile infection in the United States. N Engl J Med 2015;372:825-34. [CrossRef]

8. Cohen SH, Gerding DN, Johnson S, Kelly CP, Loo VG, McDonald LC, et al; Society for Healthcare Epidemiology of America; Infectious Diseases Society of America. Clinical practice guidelines for Clostridium difficile infection in adults: 2010 update by the society for healthcare epidemiology of America (SHEA) and the infectious diseases society of America (IDSA). Infect Control Hosp Epidemiol 2010;31:431-55. [CrossRef]

9. Tamboli CP, Neut C, Desreumaux P, Colombel JF. Dysbiosis in inflammatory bowel disease. Gut 2004;53:1-4.

10. Bien J, Palagani V, Bozko P. The intestinal microbiota dysbiosis and Clostridium difficile infection: is there a relationship with inflammatory bowel disease? Therap Adv Gastroenterol 2013;6:53-68. [CrossRef]

11. Jodorkovsky D, Young Y, Abreu MT. Clinical outcomes of patients with ulcerative colitis and co-existing Clostridium difficile infection. Dig Dis Sci 2010;55:415-20. [CrossRef]

12. Surawicz CM, Brandt LJ, Binion DG, Ananthakrishnan AN, Curry SR, Gilligan $\mathrm{PH}$, et al. Guidelines for diagnosis, treatment, and prevention of Clostridium difficile infections. Am J Gastroenterol 2013;108:47899. [CrossRef]

13. Deshpande A, Pasupuleti V, Rolston DD, Jain A, Deshpande N, Pant 
C, et al. Diagnostic accuracy of real-time polymerase chain reaction in detection of Clostridium difficile in the stool samples of patients with suspected Clostridium difficile Infection: a meta-analysis. Clin Infect Dis 2011;53:e81-90. [CrossRef]

14. Merz CS, Kramer C, Forman M, Gluck L, Mills K, Senft K, et al. Comparison of four commercially available rapid enzyme immunoassays with cytotoxin assay for detection of Clostridium difficile toxin(s) from stool specimens. J Clin Microbiol 1994;32:1142-7.

15. Ben-Horin S, Margalit M, Bossuyt P, Maul J, Shapira Y, Bojic D, et al; European Crohn's and Colitis Organization (ECCO). Combination immunomodulator and antibiotic treatment in patients with inflammatory bowel disease and clostridium difficile infection. Clin Gastroenterol Hepatol 2009;7:981-7. [CrossRef]

16. Järnerot G, Hertervig E, Friis-Liby I, Blomquist L, Karlén P, Grännö C, et al. Infliximab as rescue therapy in severe to moderately severe ulcerative colitis: a randomized, placebo-controlled study. Gastroenterology 2005;128:1805-11. [CrossRef]

17. Flegel WA, Müller F, Däubener W, Fischer HG, Hadding U, Northoff $\mathrm{H}$. Cytokine response by human monocytes to Clostridium difficile toxin A and toxin B. Infect Immun 1991;59:3659-66.

18. Ananthakrishnan AN, Oxford EC, Nguyen DD, Sauk J, Yajnik V, Xavier RJ. Genetic risk factors for Clostridium difficile infection in ulcerative colitis. Aliment Pharmacol Ther 2013;38:522-30. [CrossRef]

19. Schneeweiss S, Korzenik J, Solomon DH, Canning C, Lee J, Bressler B. Infliximab and other immunomodulating drugs in patients with inflammatory bowel disease and the risk of serious bacterial infections. Aliment Pharmacol Ther 2009;30:253-64. [CrossRef]

20. Seicean A, Moldovan-Pop A, Seicean R. Ulcerative colitis worsened after Clostridium difficile infection: efficacy of infliximab. World J Gas- troenterol 2014;20:5135-40. [CrossRef]

21. Steenholdt C, Bendtzen K, Brynskov J, Thomsen OØ, Ainsworth MA. Cut-off levels and diagnostic accuracy of infliximab trough levels and anti-infliximab antibodies in Crohn's disease. Scand J Gastroenterol 2011;46:310-8. [CrossRef]

22. Razik R, Rumman A, Bahreini Z, McGeer A, Nguyen GC. Recurrence of Clostridium difficile Infection in Patients with Inflammatory Bowel Disease: The RECIDIVISM Study. Am J Gastroenterol 2016;11:1141-6. [CrossRef]

23. Zhang T, Lin QY, Fei JX, Zhang Y, Lin MY, Jiang SH, et al. Clostridium Difficile Infection Worsen Outcome of Hospitalized Patients with Inflammatory Bowel Disease. Sci Rep 2016;6:29791. [CrossRef]

24. Singh H, Nugent Z, Yu BN, Lix LM, Targownik LE, Bernstein CN. Higher Incidence of Clostridium difficile Infection Among Individuals With Inflammatory Bowel Disease. Gastroenterology 2017;153:4308.e2. [CrossRef]

25. Abougergi MS, Broor A, Cui W, Jaar BG. Intravenous immunoglobulin for the treatment of severe Clostridium difficile colitis: an observational study and review of the literature. J Hosp Med 2010;5:E1-9. [CrossRef]

26. McPherson S, Rees CJ, Ellis R, Soo S, Panter SJ. Intravenous immunoglobulin for the treatment of severe, refractory, and recurrent Clostridium difficile diarrhea. Dis Colon Rectum 2006;49:640-5.

27. Kyne L, Warny M, Qamar A, Kelly CP. Association between antibody response to toxin $\mathrm{A}$ and protection against recurrent Clostridium difficile diarrhoea. Lancet 2001;35:189-93. [CrossRef]

28. Khoruts A, Rank KM, Newman KM, Viskocil K, Vaughn BP, Hamilton MJ, et al. Inflammatory Bowel Disease Affects the Outcome of Fecal Microbiota Transplantation for Recurrent Clostridium difficile Infection. Clin Gastroenterol Hepatol 2016;14:1433-8. [CrossRef] 